\title{
EL LEGADO DE AMPARO DÁVILA EN NARRADORAS MEXICANAS ACTUALES
}

\author{
Carmen Alemany \\ Universidad de Alicante \\ carmen.alemany@ua.es
}

Recibido: 13-04-2021

Aceptado: 15-03-2021

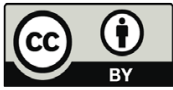

RESUMEN

A lo largo de estas páginas pretendemos indagar en la presencia de algunos rasgos de los cuentos de Amparo Dávila (1928-2020) en la obra de tres escritoras mexicanas: Cristina Rivera Garza (1964), Cecilia Eudave (1968) y Guadalupe Nettel (1973). En primer lugar, nos adentraremos en la opinión que sobre los escritos de la autora zacatecana tienen algunas de las narradoras mexicanas actuales y lo que de ellos destacan para, a continuación, adentrarnos en el peculiar uso que Amparo Dávila hizo del género fantástico y sus temáticas y cómo ello fue determinante, desde su novedad, para las obras objeto de nuestro estudio. El legado daviliano se expresa de diferentes modos, tal como indagaremos, en La cresta de Ilión (2002), de Rivera Garza, en los relatos de Eudave y en su novela corta Bestiaria vida (2008) y en El huésped, de Nettel (2006); aunque todas ellas coinciden en aprehender de aquella el uso de la ambigüedad, sus distintivas atmósferas, la hibridez discursiva y algunos tópicos del fantástico como el uso del doble, así como una manera diversa de adentrarse en la identidad.

Palabras clave: Amparo Dávila; Cristina Rivera Garza; Cecilia Eudave; Guadalupe Nettel; narrativa de lo inusual.

\section{ABSTRACT}

In the following pages, we will try to track the presence of some features found in Amparo Dávila's stories (1928-2020) in the works of three Mexican writers: Cristina Rivera Garza (1964), Cecilia Eudave (1968) and Guadalupe Nettel (1973). First, we will 
consider the different opinions that some contemporary Mexican writers have about the Zacatean author and what is especially remarkable about her writing. Then we will explore the peculiar use that Amparo Dávila made of the fantastic genre and its different themes and how that was a crucial influence on the works that we are to deal with in this essay. The Davilian legacy is expressed in many different ways, as we are to analyse, in La cresta de Ilión (2002) by Rivera Garza, in Eudave's short stories and also in her novella Bestiaria vida (2008) and El huésped by Nettel (2006) All three of them try to grasp Davila's use of ambiguity, her unique atmospheres, the hibridity of her discourse, and some recurring issues in Fantasy, such as the doppelganger and the idea of diversity whe it comes to tackle identity.

KEY-WORDs: Amparo Dávila; Cristina Rivera Garza; Cecilia Eudave; Guadalupe Nettel; the narrative of the unusual.

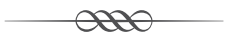

Margo Glantz, en un artículo publicado hace algunos años, «Las hijas de la Malinche» (1994), confeccionaba un mapa de narradoras que habían seguido una genealogía literaria dentro del contexto mexicano y en cuyas páginas aparecía citada Amparo Dávila a propósito de su libro Tiempo destrozado (Glantz, 2001: 302). Es nuestra intención en estas páginas recorrer esa genealogía desde Amparo Dávila, indagar qué ha ofrecido nuestra autora a narradoras posteriores y de qué manera su obra sigue perviviendo, de formas muy diversas, en las ficciones de otras, en sus hijas en la escritura.

\section{Las narradoras hablan sobre Amparo Dávila}

De forma connotada, la presencia de Dávila la encontramos, al menos, en algunas entregas de autoras como Cristina Rivera Garza (1964), Cecilia Eudave (1968) y Guadalupe Nettel (1973). Hablamos de escritoras nacidas en la misma generación y que por ello comparten, aunque sea mínimamente, una formación e inquietudes similares; y asimismo ellas aprehenderán de diferentes modos y maneras de la obra de la zacatecana. Pero la huella de Dávila, quizás de forma más indirecta, también ha estado presente en otras voces; significativas a este respecto son las palabras que algunas narradoras mexicanas, y a propósito del reciente fallecimiento de la escritora, apuntan argumen- 
tos interesantes para nuestros propósitos aún sin pertenecer, en algún caso, al ámbito de la narrativa de lo insólito. Es el caso de Daniela Tarazona (1975), autora de entre otras obras El animal sobre la piedra (2008) —una narración que se plantea desde los ámbitos de la narrativa de lo inusual-, quien apunta: «Sus personajes reflejan esa vocación y traspasan el tiempo para abrir las compuertas cotidianas y darle lugar a lo extraño. Su escritura singular opera por el desconcierto, como si fuera un fantasma conocido. La revelación de los filos de la cotidianidad y la apertura de sus dimensiones hacia abismos oscuros que forman los universos inquietantes desvelados en sus cuentos, serán un referente inextinguible en la literatura» (González, 2020). Por su parte, Socorro Venegas (1972) la tilda de autora con algunos destellos fantásticos y alucinatorios, lo cual es interesante para nuestros intereses por lo que argumentaremos en páginas ulteriores:

incursionó en la literatura de lo extraño o lo insólito, ella prefería que su obra no se encajonara dentro del género fantástico, pues sentía que había, y hay, muchos prejuicios cuando se habla de cuento fantástico. Situó a personajes femeninos en una vida cotidiana que poco a poco iba convirtiéndose en otra cosa, en una pesadilla, en realidades alternas que terminaban revelando con profundidad la verdadera materia oscura del mundo (González, 2020).

Para añadir a continuación: «Su obra abrió caminos para las nuevas generaciones de escritores que han explorado lo insólito. Durante mucho tiempo fue considerada una autora de culto, pero han sido precisamente sus lectores los que la han ido colocando en el lugar que le corresponde» (González, 2020).

Otra autora, nacida también en los setenta y prosista de lo insólito, Iliana Vargas (1978), nos ofrece los siguientes comentarios: «descubrí una conexión particular con su visión de lo sobrenatural, lo ominoso y lo onírico en elementos y situaciones de la realidad cotidiana de mujeres que forman parte de distintos estratos sociales», para terminar afirmando que «su nombre aparece cada vez que alguien me pregunta cuáles son mis influencias o mis escritoras favoritas; la releo y escribo sobre ella cada vez que puedo» (González, 2020).

\section{LAS PECULIARIDADES DEL FANTÁSTICO DAVILIANO}

Podemos deducir a través de estas palabras, y la de otras autoras que podríamos sumar, que el fantástico de Amparo Dávila se escudó en unos parámetros que no eran los usuales en su época —al menos el que estaban 
escribiendo los autores- y logró configurar un discurso en cierta medida nuevo, y muy actual — de ahí la seducción que se establece con las narradoras mexicanas de hoy - en el que primó algo tan en boga en la época actual como lo es la hibridez discursiva (fantástico, terror, extraño, lo siniestro), más que la genérica. Asimismo, se implicó más social que políticamente con la clase media de la época, y es a este estrato al que pertenecen sus personajes; y son las hijas de aquellas madres de clase media de las que nos hablara Dávila en sus relatos las que hoy nos ofrecen, continuados, los discursos que ella elaboró. Nuestra autora, al igual que sus compañeras de generación, entre las que cabría citar a Rosario Castellanos, Elena Garro, Josefina Vicens, Inés Arredondo y Guadalupe Dueñas, propusieron en lo narrativo una «autonomía discursiva», así como una «VOZ» y una «presencia» fruto de la disciplina y de la experiencia. Magali Velasco destaca que de entre ellas, Dávila y Dueñas, «mediante símbolos y alegorías, elementos de alto riesgo creativo, ambas escritoras entrelazaron sistemas narrativos de óptima factura. Dávila y Dueñas recrearon temáticas protofemeninas y protofantásticas: el hogar, el matrimonio, la agresión masculina, la represión sexual, la soledad, la vejez, el doble, las damas fantásticas» (2007: 126-127).

Pensamos que una de las aportaciones más sobresalientes de la autora zacatecana fue elaborar - ya lo hemos señalado- discursos híbridos, tan poco usuales en aquellos tiempos y tan de actualidad en nuestros días, fundamentalmente de la mano de las narradoras de lo insólito. Ya en la década de los sesenta, Mario Benedetti, al reseñar el libro Música concreta, desde un agudo ojo crítico anotó estas significativas palabras: «Es tan difícil encasillarlos en el realismo como en la literatura fantástica, ya que temerariamente oscilan entre uno y otra» (Álvarez, 2016: 459). ${ }^{1} \mathrm{Y}$ al hilo de lo comentado por el uruguayo traemos a colación lo que la propia autora dirá años más tarde: «Mis cuentos no son necesariamente "fantásticos". Yo por lo menos no los defino así, ni quiero definirlos siquiera. Practico una línea intermedia entre las dos tendencias predominantes: la realista y la fantástica. Buscando llegar a un vértice en que realidad y fantasía se toquen y se fundan, ya que para mí ni la una ni la otra son absolutos. En toda realidad hay mucho de fantasía y en toda fantasía hay mucho de realidad» (Dávila, 2004: 452).

Ya en el siglo XXI, la crítica, cuando progresivamente se irá acercando más a su obra, apostará por encuadrarla en la creación de un discurso ambiguo, lle-

1 La propia Amparo Dávila ofreció este recorte de prensa a Adriana Álvarez Rivera que fue incluido en su Tesis doctoral. Con el título «Horror al alcance de todos» fue publicado en La Mañana, Montevideo, 30 de julio de 1965, en el suplemento «Al pie de las letras». 
no de metáforas y otros recursos tropológicos que marcarán la singularidad de su escritura. Rafael Lemus, por ejemplo, desestima la etiqueta de lo fantástico para definir la obra de nuestra autora y propone una forma diferente de acercarse a la interpretación de sus cuentos, nombrando al elemento extraño o insólito que componen sus relatos como «eso»; que según él se trata de algo real que si no existe en el mundo sí está presente en la obra de la autora: «lo más valioso de la obra de la zacatecana es el modo en que vuelve reales las sombras que acosan a sus personajes» (Lemus, 2009). Y Leticia Lilia García Peña insiste en esos mismos parámetros al afirmar que «la escritura de Amparo Dávila explora e incita aquellas dimensiones en las que lo cotidiano y conocido se toca con lo insólito e inexplicable, y en los parámetros de serenidad y causalidad son alterados y aniquilados» (2018: 89). ${ }^{2}$ Y al hilo de estos discursos, Aída T. González Zimmer subraya que «la ambigüedad de la narrativa de Dávila despertará la controversia entre los estudiosos de su obra, y centrará la crítica en las cuestiones que buscan una clasificación o inclusión de su producción cuentística en algún género específico, generalmente, aceptando que sus cuentos se decantan mayoritariamente por su carácter fantástico, pero también gótico o insólito» (2019: 13).

Son variados los temas y los discursos en los que se internó Amparo Dávila, y pareciera que cada uno de ellos requiriese un modo peculiar de tratamiento dentro de la ambigüedad discursiva — tan importante y decisiva en el género fantástico-, y así lo podemos detectar en este amplia y detallada cita de Juan Ramón Vélez García:

El texto compuesto de distintos fragmentos que consignan distintas vivencias insólitas o angustiantes con base autobiográfica («Tiempo destrozado» y «El patio cuadrado»), crónicas sobre el acoso ejercido por entidades cuya naturaleza negativamente o malinterpretan las intenciones de un desconocido («Tina Reyes»), disquisiciones sobre la crueldad ejercida sobre sí mismo o sufrida por otros seres («Fragmentos de un diario», significativamente titulado en su primera versión «Fragmentos de diario de un masoquista», y «Alta cocina»), la amenaza secular que constituye la posibilidad del regreso de los muertos («La rueda») o de seres cuyo advenimiento o clamor procede de otras dimensiones («El espejo», posiblemente uno de los cuentos mexicanos más próximos al «horror cósmico»), así como la denuncia de la situación de una esposa confinada a «los sombríos túneles del miedo y el desencanto» por la actitud de un marido brutal e incomprensivo («La noche de las guitarras rotas», que recupera el papel perturbador del sonido inarmónico o estridente ya presente en «Música

2 Vélez García también se muestra disconforme con la etiqueta de escritora de literatura fantástica; para él, es el mundo de la locura y la cordura los que se unen para configurar la realidad humana (2015: 155). 
concreta»). Se hacen patentes varios ingredientes de lo gótico y lo fantástico (la ambigüedad interpretativa acerca de los hechos, lo nocturno y lo onírico, las convulsiones psíquicas, el crimen, la muerte...) (2015: 155-156).

Estamos ante temas de palpable actualidad, de ahí el atractivo que la obra daviliana tiene entre las autoras mexicanas de hoy; aunque señalamos que nuestra escritora no mira tan directamente hacia el interior de los personajes como sí lo harán «sus hijas» en la escritura. Podríamos decir que es fruto de nuestro tiempo que la irrealidad tenga muy en cuenta el espacio interior frente al exterior; las escritoras de hoy desconciertan a los lectores porque lo aparentemente insólito se interpreta como la expresión maníaca del sujeto esquizofrénico posmoderno. No hay una contradicción directa entre realidad y ficción, pero tampoco se presuponen automáticamente los hechos como realidades que entran a formar parte de la lógica de la normalidad. Es el suyo un fantástico ambiguo que creemos desemboca en lo que hemos denominado narrativa de lo inusual; ${ }^{3}$ y como ya hemos señalado en alguna ocasión, Amparo Dávila sería una de sus precursoras (Alemany, 2016: 132 y 2020: 10). ${ }^{4}$

La de Dávila es una escritura que se basa en la capacidad de sugerir los elementos fantásticos a través de la constante ambigüedad, el desconcierto y la apariencia, proponiendo una continua relectura de la realidad que se revela desde otro punto de vista: el insólito, lo misterioso y lo irracional. Y la esencia fantástica queda a merced del lector — como también en la narrativa de lo inusual ${ }^{5}$ que es quien debe acometer un trabajo de interpretación subjetiva clausurando el sentido definitivo y a la vez particular del relato. ${ }^{6}$

3 Para más información sobre la narrativa de lo inusual, véase Alemany (2016), (2019) y (2020), y García-Valero (2019).

4 «El intimismo y la poeticidad del lenguaje, tan notable en sus novelas [nos referimos a Bestiaria vida de Ceclia Eudave y a El animal sobre la piedra de Daniela Tarazona], como esa manera peculiar de acceder a otras vías de la realidad proceden, creemos, de narradoras mexicanas del medio siglo como Amparo Dávila o Guadalupe Dueñas — más la primera que la segunda—, a cierta distancia de Inés Arredondo o Elena Garro. Creemos que Tiempo destrozado de Amparo Dávila, y básicamente los relatos "La celda", "La señorita Julia" o "El espejo" bien podrían ser referentes de esta "narrativa de lo inusual"» (Alemany, 2016: 132). 5 «En la narrativa de lo inusual lo que prima es la incertidumbre, los hechos transcurren en un plano real —a veces en el onírico o en el delirante-, y el autor abandona al leyente en su perplejidad, pues esta ambigüedad tiende a provocar la vacilación interpretativa del lector. Por tratarse de textos muy ambiguos, el lector puede dudar de la naturaleza de esa realidad; pero insistimos, al final esta aflora con toda su contundencia» (Alemany, 2019: 313).

6 Como nos advierte Adriana Álvarez Rivera: «Los cuentos de Dávila no son transgresores por sus temáticas ni tampoco subvierten, como las vanguardias o el absurdo, a través de las rupturas formales y de la lógica interna que presentan: violan las consignas porque confrontan al lector con la incertidumbre, obligándolo a realizar hipótesis para encontrar "respuestas" en el texto, pero también forzándolo a asumir que el mundo, tal como lo conocemos, revela rendijas tras las que se oculta, como afirma Dávila en sus entrevistas, otra realidad, oscura, misteriosa, honda e inexplicable ante la cual solo resta actuar como Mariana, la protagonista del último cuento: clavar las unas en las palmas de las manos y abrir los ojos» (2016: 412). 
Cerramos este epígrafe con las palabras de Miguel Carrera Garrido, pues a través de estas se trasluce qué es lo que las hijas davilianas aprehenden de la zacatecana:

La novedad de cuentos como los de Dávila es el protagonismo del cómo, por encima del qué, el hecho de que la enunciación logre, por sí sola, suscitar el desasosiego, la incertidumbre; cosa que no vuelve irrelevante el contenido, pero sí lo envía a un segundo plano, desde el que, aun así, conoce un inusitado ensanchamiento semántico. Los espantos tradicionales se ven, así, desdibujados en su materialidad y efectismo, para adquirir, a cambio, un mayor relieve en el campo metafórico. Todo ello enriquece, como digo, el resultado, alejándolo de una excesiva literalidad y conectándolo con planteamientos que pretenden algo más que el impacto físico o emocional, o la simple duda epistemológica (2018: 188-189).

\section{LAS HIJAS DE LA ESCRITURA DAVILIANA}

Tal como señalábamos en líneas anteriores, centraremos nuestro recorrido en tres autoras que creemos son herederas directas del legado de Amparo Dávila: Cristina Rivera Garza, Cecilia Eudave y Guadalupe Nettel. Todas ellas lo harán desde la novela, aunque curiosamente nuestra escritora nunca publicó en este género, se ciñó a la escritura de cuentos que decisivo fue para la llamada Generación de Medio Siglo de la que ella formó parte. En Eudave y en Nettel también podemos adivinar la presencia daviniana en algunos relatos.

\subsection{Cristina Rivera Garza ${ }^{7}$}

En 2002 Cristina Rivera Garza publicó La cresta de Ilión, obra en la que Amparo Dávila es uno de sus personajes relevantes: ella y sus dobles. La autora

7 En la mencionada Tesis de Adriana Álvarez Rivera se transcribe la entrevista que esta le realizó; y a propósito de la novela de Rivera Garza Amparo Dávila responde del siguiente modo:

AAR.- Quiero preguntarle cómo ve la relación de su obra con algunas otras, más o menos contemporáneas, por ejemplo, estaba pensando en Cristina Rivera Garza, que escribió La cresta de Ilión.

AD.- Sí, siendo yo ahí personaje...

AAR.- Sí, un personaje desaparecido, y una Amparo Dávila Falsa y una Amparo Dávila Verdadera...

AD.- Bueno, ya no se sabe...

AAR.- ¿Cómo ve usted esa relación entre el libro de Cristina Rivera Garza y su obra?

AD.- Yo siento que el libro en sí se diluye un poco, que no concreta muy bien, pero tal vez es difícil ser juez y parte porque si fuera sobre otra persona yo tendría una visión más objetiva, más clara, que tratándose de mi propia persona.

AAR.- Y de su literatura, además...

AD.- Y de mi literatura, entonces le digo es muy difícil ser juez y parte, pero siento como juez que se le pierde algo. No la siento muy concreta, o será porque yo no soy novelista; es una situación difícil porque le gana a uno el crítico o el creador... (Álvarez, 2016: 445). 
tamaulipa presenta la Amparo Dávila madura —o la «Desaparecida»—, a una joven Amparo Dávila que pertenece a las «Emisarias», o las copias (que son a su vez dobles) de Amparo Dávila que intentan ayudar a la «Desaparecida». Sin embargo, y como afirmó, Christopher Domínguez Michael: «El motivo literario de La cresta de Ilión es [Amparo] Dávila. Escribo motivo y no personaje, pues Rivera Garza hizo de Dávila, de sus textos, de sus fotografías en las cuartas de forros, de su leyenda (si es que la tiene) una potencia» (2012: 111).

Al comienzo de la novela, en la casa del médico protagonista se presenta una extraña mujer que le dice: «Soy Amparo Dávila» (2002: 15), para espetarle páginas después: «Te conozco de cuando eras árbol. De aquellas épocas» (2002: 19), frase que nos remite directamente a la obra de la zacatecana, en concreto al relato «Muerte en el bosque»: "Sintió entonces nostalgia de los árboles, deseo de ser árbol... ("Ahora lo encuentro, ahora lo encuentro", decía la mujer)... vivir en el bosque, enraizado, siempre en el mismo sitio, sin tener que ir de un lado a otro, sin moverse más» (Dávila, 2009: 54). Por eso no es de extrañar que la crítica haya buscado las relaciones entre esta obra y los relatos de Dávila, pues son evidentes o explícitas en no pocas ocasiones.

El trabajo de establecer los vasos comunicantes entre esta novela y la obra de Amparo Dávila ha sido el factor central que ha ocupado hasta ahora a buena parte de la crítica (Cf. Zaca Guevara, 2005; Mercado, 2007). Para resumir estas concomitancias nos remitimos a las palabras de Gabriela Mercado quien afirma que «Existe, pues, una relación muy importante, sobre todo con algunos de los cuentos de su primer libro Tiempo destrozado (1959) y el último, Árboles petrificados (1977). Asimismo, el ambiente de misterio y fantasía, característico en su obra completa, se ve presente en la novela de Rivera Garza, aunado a ciertas imágenes recurrentes como son el mar, las aves, la lluvia, la soledad» (2007: 49). Y siguiendo la terminología de Gérard Genette, nos dice la autora del artículo: «Son tres los tipos de relaciones transtextuales presentes en La cresta de Ilión: hipertextualidad, intertextualidad y paratextualidad» (2007: 49). Asimismo, «La toma de imágenes es amplia. Los cuentos de donde Rivera Garza ha obtenido imágenes son "Muerte en el bosque", "Tiempo destrozado", "Final de una lucha" y "Moisés y Gaspar" de Tiempo destrozado; y "Árboles petrificados", "El patio cuadrado", "Griselda" y "El pabellón del descanso" de Árboles petrificados» (2007: 49-50). En definitiva, la autora «dialoga» con la obra de Dávila en La cresta de Ilión al igual que lo hace en La muerte me da (2007) con los textos de Alejandra Pizarnik y, años después, y quizás de una manera mucho más explícita con los de Juan Rulfo en Había neblina, humo o no sé qué (2016). 
Es en este punto en el que nos interesan principalmente las palabras de Rivera Garza sobre la intencionalidad de la obra y qué es lo realmente decisivo de aquella en la suya. De las veces que la tamaulipa ha hablado de Dávila, tomamos la entrevista que Laeticia Rovecchio Antón le realizó poco después de la muerte de la zacatecana. De ella «me interesaron, sobre todo, sus atmósferas», para añadir el motivo por el cual la zacatecana se convirtió en eje de su obra: «Como en aquella época su obra no recibía la atención que, merecidamente, recibe ahora, su caso me pareció perfecto para una trama en que la desaparición cultural va ligada con la violencia física. En lugar de "homenajearla", que es una palabra que siempre implica distancia y verticalidad, me gustaría decir mejor que trabajé con algunas de sus estrategias de escritura: con ella, quiero decir, no sobre ella» (Rovecchio, 2020). Y en una pregunta anterior, Rovecchio Antón se refiere a la traducción al inglés de la obra, que se publicara en el 2017, a lo que responde Rivera Garza: «Así me di cuenta de que, de muchas maneras, el tiempo de La cresta de Ilión era justo ahora: los temas que me habían obsesionado entonces - la división mortífera de géneros, la desaparición cultural y física impuesta sobre las mujeres, la prepotencia de las fronteras en el sentido más amplio del término- eran parte central de las conversaciones del hoy» (Rovecchio, 2020). A partir de esta edición, «me di a la tarea de borrar y / o agregar secciones enteras. Esa nueva versión en inglés se transformó en el original que volvió a ser traducido al español y que primero se publicó en México con Random House y ahora con Tránsito» (Rovecchio, 2020).

Es en este punto en el que debemos reflexionar sobre dos cuestiones que se nos antojan importantes. Por una parte, la intencionalidad última de esta obra que, más allá del sincero homenaje, alude a otros temas que a Rivera Garza le motivan y preocupan; cuestiones como las desapariciones de mujeres - tan presentes en el México de hoy - y que se muestran en la novela mediante el personaje de «La Traicionada» que viene enferma de algo que se califica ambiguamente como la «epidemia» y que, más adelante, se relacionará con esta: «La desaparición es una condición contagiosa» (Rivera, 2002: 30), que hace referencia a su vez a las desaparecidas de Tijuana. Asimismo, las páginas de Rivera Garza apuntan a la preeminencia de los sistemas patriarcales; a cuestiones como el bien morir: «Los conminaba a morir con dignidad, a exigir un trato justo, a demandar por lo menos un ataúd, a abolir la fosa común» (Rivera, 2002: 46). Pero el título de la novela nos remite a una cuestión central, como es el género, tan en boga en nuestros días; una cuestión ontológica de si se es hombre o mujer, más allá de la preferencia, tal como se nos induce desde el psicoanálisis más tradicional. Para Felipe A. Ríos Baeza, «Des- 
de ahí, desde el reconocimiento del hueso que identifica la sexualidad de una persona, es que se parte para señalar que no hay reconocimiento de género y no hay lenguaje que dé cuenta de ese género que se conciba separado de la escritura, cuestión que será tema, luego, de novelas tan deconstructivas como Lo anterior (2004) y La muerte me da (2007)» (2019: 114). Y como resume Emily Hind: «Los aspectos centrales de La cresta de Ilión, entonces, abarcan la carencia de identidad estable, la carencia de una lógica esperada y la carencia de una trama resuelta» (2005: 37). De ahí la presencia de un narrador no fiable que advirtiera Marta Sanz en su nota sobre la novela, lo que nos lleva a destacar la presencia de narradores no fiables tan presente en la narrativa de lo inusual, tal como ha destacado Benito García-Valero (2019: 326); y siguiendo a Sanz, Rivera Garza trabaja «con la ambigüedad de una voz que no sabemos si es fantasmagórica o matérica, pasto de la enfermedad o sanadora, si lleva una marca de masculinidad o feminidad en la cresta de Ilión: el cuerpo está lleno de claves óseas y la cresta iliaca sirve para identificar el género» (2020). Y es esa ambigüedad precisamente la que potencia lo fantástico, pero fundamentalmente el fantástico de hoy llevado a cabo por las narradoras de lo inusual; esa ambigüedad que oscila entre lo real y lo irreal a cada paso. Como apuntara Gabriela Mercado,

De todos los personajes, los únicos que pueden considerarse como reales son la protagonista misma, los enfermeros (cuyos nombres ella ha asignado a partir de un cuento de Dávila, «Moisés y Gaspar»), el enfermo que se tira por la ventana y, seguramente, el Director General. Los demás (la Amparo Falsa y la Verdadera, la Traicionada, las Urracas y los demás ambientales) son parte de su ficción, así como las visitas a las Ciudades del Sur y del Norte, la posesión del jeep e, incluso, la recuperación de los manuscritos. Al final, ella misma deja saber al lector que todo ha sido una invención de su mente y que nada de lo que ha venido relatando es real o, mejor dicho, que nada se debe tomar muy en serio: «En ese mediodía, por ejemplo, no existió el mí, no había ninguna Amparo Dávila sobre el mundo; simplemente estaba abriendo la puerta de mi casa después de una ausencia aparentemente larga» (2007: 48).

¿Es esta una novela fantástica? Creemos que sí y con características propias de lo inusual, y para ello nos remitimos al artículo de Verónica Saunero-Ward, «La cresta de Ilión: lo fantástico posmoderno». En él se apunta que los «personajes no llevan nombre ni características que permitan en la lectora la ilusión de la verosimilitud» (2006: 175), algo habitual en la narrativa de lo inusual; para anotar a continuación que «si el lector desconociera la existencia de Amparo Dávila, escritora mexicana, se perdería la dimensión metaficcional 
de La cresta de Ilión, pero persistirían, en la novela, la ambigüedad entre la realidad y la irrealidad, la ambigüedad en la identidad de los personajes y en el género de los mismos, todas particularidades que refuerzan el carácter fantástico de la obra» (2006: 175). Como se apunta en la novela, lo verdaderamente importante es definir qué es real: «Ya me había dejado yo de preguntar sobre la verdad, para empezar a explorar el fundamento mismo de lo real» (Rivera, 2002: 74).

\subsection{Cecilia Eudave}

Cecilia Eudave, siempre que ha tenido ocasión, ha destacado la importancia que Amparo Dávila ha tenido para ella a la hora de escribir sus relatos y novelas. Si bien no encontraremos demasiados intertextos de la obra de la zacatecana en la de la tapatía, si notamos una pareja actitud a la hora de enfrentar los textos; tomando las debidas distancias temporales, además de las estilísticas, entre una y la otra. En su primer libro, Técnicamente humanos (1996), estamos ante la presencia arrolladora de Italo Calvino, pero será en Registros de imposibles (2000, 2006), y en algunos escritos puntuales de su obra posterior — especialmente su novela breve Bestiaria vida (2008) — donde se recoja con todo su peso la presencia sutil de la zacatecana.

Tras el fallecimiento de la escritora de Música concreta, Eudave señala a Beatriz García cuáles son sus impresiones de los relatos de Dávila, y creo que de sus palabras podemos extraer unas primeras conclusiones sobre qué aprehende de ella; Dávila, según la autora tapatía,

le da una vuelta de tuerca al espacio femenino por medio de la literatura no mimética, a través de una escritura singular e inquietante. Logró crear excelentes atmósferas para que sus personajes femeninos pudieran liberar su otro yo: el monstruoso. Monstruos y seres fantásticos que producen catarsis y la toma de la conciencia del ser reprimido; Dávila consigue despertar la identidad sofocada o rechazada de las mujeres dominadas por las imposiciones sociales de la época que le tocó vivir (2020).

No son pocos los personajes femeninos, al igual que en Dávila, que protagonizan los escritos de Eudave; mujeres que intentan «liberar su propio yo» del que nos habla en el párrafo anterior, mujeres con una «identidad sofocada o rechazada» por las imposiciones sociales como en su relato «Insignificantes» (2013: 48-77), perteneciente a En primera persona. Situaciones que deri- 
van hacia la locura, como podemos leer en «La quinta de las celosías» (2009: 29-38) de Dávila; y Eudave acude a esa locura — aunque en esta ocasión sin tintes fantásticos - en «Las vigilantes» (2006: 61-65), relato presidido también por el uso de lo siniestro y de lo absurdo tan presente en «Música concreta» (2009: 97-111). Atmósferas sustanciadas por lo depresivo, por el encierro, que de manera sobresaliente se trasluce en un relato, recientemente publicado en la revista Luvina, «Polvo otoñal»:

Toqué la banca de madera oscura donde estaba sentada y comenzó a crujir: el frío de mi mano le confirió la dureza de lo que se va a reventar. Por dentro sentí todo el hielo y al mismo tiempo el fuego que me ponía febril por las noches, que pasó de ser una sensación esporádica a constante en los últimos meses. Ahora ya no podía disimular el desasosiego, y los objetos explotaban en polvo como si ahí les depositara mi ira, como si tantos años conteniéndome, tratando de disimular, de ser condescendiente con esta condición infame, perversa, con este don inservible de convertir todo en polvo, en tristeza, me regalara, por fin, una emoción distinta al desencanto. Así que esto es sentir algo luminoso, me dije (Eudave, 2020).

Asimismo, la presencia del doble, tan cara a la escritura fantástica, pulula por los textos de Eudave: «Eva entró por la ventana» (2013: 87-104) y «Técnica mixta» (2006: 57-60) podrían ser un buen ejemplo; como de forma magistral lo utilizó Amparo Dávila en otros tantos. ${ }^{8}$

El doble, pero sobre todo la presencia de personajes afines a los de Amparo Dávila, se harán presentes en la novela de Eudave Bestiaria vida (2008); pero con algunas diferencias que conviene denotar. Mientras que en la zacatecana las imposiciones sociales privan a las mujeres de sentirse realizadas, de protagonizar su identidad; en el caso de Eudave, ya en pleno siglo XXI, es la sociedad de consumo la que ahoga y no permite a su personaje principal encontrarse consigo sí misma. En las páginas de Bestiaria vida encontramos la denuncia al inconformismo, a los roles establecidos por la sociedad y en los que algunas mujeres no se sienten ni cómodas ni identificadas. De ahí que una

8 Deberíamos atender en este punto a las distinciones que de la presencia del doble hace Adriana Álvarez Rivera en la obra de Amparo Dávila: «Con respecto al tema del doble, la propuesta de la mexicana es plural: por una parte, en "Final de una lucha" aparece de manera literal otro Durán, quien encarna la figura tradicional del Doppelgänger, entendida como un ser exactamente igual al otro, pero cuya historia representa, en este caso, una realidad alternativa a la del original. Otros personajes también manifiestan un tipo de duplicidad (como son los casos de Paulina y su sobrina en "Detrás de la reja", Sergio y Marcela en "Música concreta", los hermanos Kraus en "Moisés y Gaspar" o madre e hijo en "El espejo") o un encuentro con sus dobles, en medio de una narración de estilo onírico (la mujer que se enfrenta a sí misma en diferentes etapas de su vida en "Tiempo destrozado")» (2016: 410). 
nueva búsqueda de la identidad se convierta en uno de los ejes centrales dentro de la narrativa de lo inusual, a la que pertenece la novela eudaviana. Sobre la identidad de las mujeres, Cecilia Eudave se mostrará contundente en un texto que dedicó a Amparo Dávila y que fue incluido en Diferencias, alteridades e identidad (Narrativa mexicana de la primera mitad del siglo XX):

Lo monstruoso femenino, desde el discurso de Dávila, funciona como una metáfora de la aniquilación de la identidad propia: por un lado no pueden ser lo que desean, pues resulta perjudicial para la sociedad y rompe con los núcleos sociales (la familia, el matrimonio, la religión, el trabajo); y, por el otro, si se es lo que se desea acaban sometiéndose a la realidad que impone lo homogéneo como punto de estabilidad: debes casarte, debes contener tu ira, debes obedecer a la familia, cumplir con el rol tradicional de la mujer en el contexto de los años en los que se inscriben sus cuentos (2015: 148).

Y Eudave lo hará a través de seres monstruosos que intermedian para contar la realidad tal como la siente la protagonista. Estos monstruos mitológicos, y en ocasiones distópicos que encontramos en su novela, se insertan en la realidad cotidiana y, además, se comportan siguiendo los parámetros del ser humano. Por tanto, la autora no quiere desprenderse de la realidad, como tampoco Amparo Dávila pretendía desprenderse totalmente de ella; la protagonista de esta historia proyecta un inconsciente inestable en una realidad que interpreta como atroz, como no pocas de las protagonistas davilianas. Por esta razón, la presencia de los sueños y lo onírico, tan usual en ambas autoras, se entremezcla con el tratamiento de lo insólito hasta el punto de que el lector se solidariza con esta visión caótica y vacilante de la realidad. En este escenario, los límites entre lo real y lo imaginado se desvanecen; lo fantástico sirve de instrumento para crear un delirio que transita entre lo onírico y lo real y que sitúa al lector en la encrucijada de estos dos planos, hecho que implica una constante incertidumbre. Una incertidumbre que se acompaña de peculiares atmósferas, algo que las obras de las tres autoras que estamos analizando tienen en común con las de Amparo Dávila; esta ambientación resulta crucial para potenciar el carácter de extrañeza de los relatos, los rumores fantásticos, pues prima lo ambiguo, la vacilación, la perplejidad.

Pareciera que ambas detectan la presencia de lo fantástico en todas partes, y ese carácter insólito que se encuentra en la realidad no les histeriza, lo asumen, lo aceptan, no las paraliza; más bien al contrario, las vuelve más activas: «me acerco a los mundos de Dávila que confeccionan el espacio fantástico no solo como lugar libertador del otro yo: el monstruoso, sino del espacio 
íntimo e interior propio de lo femenino en sus relatos frente al espacio exterior, lugar privilegiado de lo masculino» (Eudave, 2015: 147).

La escritura de Eudave es de umbrales, como también lo fue la de Dávila. Al igual que en la obra de la zacatecana podemos encontrar en la eudaviana relatos de clara urdimbre fantástica y otros que no lo son tanto; que si bien en la primera tienden a lo siniestro, en la autora tapatía se orientan hacia esa modalidad de lo fantástico que es lo inusual y de la que Amparo Dávila fue predecesora como ya hemos dicho.

Cecilia Eudave apuesta por un insólito en el que el conflicto se relaciona directamente con la inestabilidad del sujeto posmoderno; una inestabilidad según la cual realidad y ficción se funden en el laberinto interior de sus protagonistas y cuyo resultado es un testimonio íntimo y delirante. Amparo Dávila, por su parte, creó unos personajes que transitaban entre lo onírico y lo real situando al lector en la encrucijada de estos dos planos, hecho que implica una constante incertidumbre. Y como dijera Eudave al final del mencionado texto: «Las mujeres de la generación de medio siglo, con o sin la soga al cuello, trazan con sus textos las primeras rutas para la configuración de un espejo propio donde se miran y se representan, ellas saben lo que son, ahora falta que el otro las reconozca, pero ese ya no es un problema de identidad sino de reconocimiento» (2015: 150). Como «Las hijas de la Malinche», Eudave, en pleno siglo XXI, sigue la estela davilina pero con los nuevos instrumentos que la narrativa y otros estándares sociales le ofrecen.

\subsection{Guadalupe Nettel}

El universo narrativo de Guadalupe Nettel está asociado por momentos a no pocos de los temas davilianos, y no solo a «El huésped». Lógicamente, el título homónimo entre el relato de Dávila y la novela de Nettel es ya un reclamo; pero hay notables diferencias, tal como ha reseñado Oswaldo Estrada; diferencias que aúnan la novela de Nettel con La cresta de Ilión de Rivera Garza:

Como era de esperarse, no pocos lectores de El huésped han observado la coincidencia entre el título de esta novela y el cuento de Amparo Dávila «El huésped», aquel que forma parte de su colección Tiempo destrozado (1959). No obstante, la diferencia entre ambas piezas literarias es radical. En el cuento de Dávila, la protagonista logra vencer al huésped indeseable que su marido ha traído a casa como recordatorio de su poder e imposición irrefutable. Ayudada por su empleada Guadalupe, la protagonista encierra al huésped en un 
cuarto al fondo de su casa, hasta matarlo «sin aire, sin luz, sin alimento». Aquí, en cambio, en un giro de ciento ochenta grados, Nettel deja que su protagonista acepte a su huésped, a esa Cosa que representa todos sus miedos, como parte esencial y sello distintivo de su verdadera persona. Bien mirado, en realidad el huésped de Nettel se parece mucho más al personaje llamado Amparo Dávila en la novela La cresta de Ilión. Porque a través de esta visita inesperada que se instala en su casa con total familiaridad, el protagonista de la novela de Rivera Garza emprende un viaje de autoconocimiento, a través del cual acepta sus «deseos» y sus «miedos», hasta vocalizar su mayor «secreto»: el de su sexualidad — ¿masculina, femenina? - situada en medio de dos polos opuestos (2014: 262-263).

Sin embargo, a través de las siguientes palabras de Maricruz Castro Ricalde podemos establecer evidentes vasos comunicantes desde la perspectiva temática entre ambas escritoras, y no solo a partir del relato de «El huésped».

En El huésped (2006), El cuerpo en que nací (2011) y Después del invierno (2014), las protagonistas se violentan a sí mismas, a través del aislamiento y la automarginación. Es casi imposible la integración de sus narradoras a los núcleos sociales más evidentes: la familia, el vecindario, la escuela, la comunidad o la vida en pareja. En el primero de estos títulos, Ana está cierta de ser habitada (muy a su pesar) por una entidad que se va apoderando de ella hasta sumirla en un mundo de tinieblas. El contacto con el mundo de los invidentes y la ceguera que se le manifiesta posteriormente agudizan la conciencia de que su cuerpo es un campo de batalla entre un «yo» y un «otro», La Cosa. El botín es el cuerpo mismo que será dominado por quien triunfe en esa lucha. En El cuerpo en que nací, el parche sobre el ojo derecho de la protagonista la marcará desde su infancia como alguien que ve de manera distinta su contexto porque ella, a su vez, es vista como diferente. Después del invierno redunda en los miedos experimentados por sus personajes, en la conciencia del grado de anormalidad que implica existir en los márgenes de las grandes urbes (Nueva York y París) (2017: 66-67).

Además de lo aquí expuesto, hay una ligazón evidente que es la duda sobre lo real y lo imaginado que de forma constante aparece en ambas escritoras y que lo vincularía a uno de los aspectos esenciales de la narrativa de lo inusual; como también que El huésped oscila entre el relato fantástico y el metafórico, tal como señaló Elsa Cano en una nota que sobre esta novela escribiera para advertirnos asimismo de los «vasos comunicantes con El otro de Borges, El pabellón de Chéjov, La Castañeda de Rivera Garza, El huésped de Amparo Dávila, En la ardiente oscuridad de Buero Vallejo y, desde luego, con Dr. Jeckyl y Mrs. Hyde» (s/f). Es el tema del doble, tan presente en las hijas davilianas, tal 
como hemos visto en líneas anteriores, el que establece el cordón umbilical entre ambas escritoras. Como advirtiera Carolyn Wolfenzon, «el tema del doble sí aparece en todas estas novelas. En El cuerpo en que nací, la protagonista lee: El Dr. Jekyll y Mr. Hyde, El retrato de Dorian Gray, Los elíxires del diablo y El Horla. En estas novelas, el bien y el mal están representados siempre en dos personajes distintos a pesar de que muchas veces compartan el mismo cuerpo, como en el emblemático caso de la obra de Stevenson» (2017: 42). ${ }^{9}$ Basta acudir a la primera línea de El huésped en el que la protagonista, Ana, dice lo siguiente: «Siempre me gustaron las historias de desdoblamientos, esas en donde a una persona le surge un alien del estómago o le crece un hermano siamés a sus espaldas» (Nettel: 2006: 13), para agregar en páginas sucesivas: «a partir de ese año y, creo que, con cierta razón, comencé a tener miedo de mí misma. Miedo de La Cosa que sentía crecer en mí como una larva en su crisálida; miedo de los cambios que se producían en mi cuerpo, miedo de los actos que podía cometer sin darme cuenta» (Nettel: 2006: 21).

Cierto es que existen diferencias entre ambos textos, tal como hemos reseñado; pero una de las más evidentes es que mientras en Amparo Dávila el «huésped» es ajeno, es exterior, en Nettel es interno, surge del propio yo: «En Nettel, el doble es la figura de un solo cuerpo indivisible cuyos cambios son espontáneos y donde el paso de Ana a la Cosa (su otro yo) no está relacionado con factores ajenos que lo determinan, ni con ciertas gestualidades que pueden advertirle al lector quién de los dos "yo" está comenzando a aparecer» (Wolfenzon, 2017: 42). Lo que nos llevaría una distinción entre las hijas davilianas y la autora zacatecana como lo es que aquellas se amparan, de manera usual, en la primera persona mientras que Dávila recurre fundamentalmente a la tercera persona; con lo cual nos lleva a otra cuestión diferencial y de calado como lo es la cuestión de identidad —o quizás una identidad diferentetan presente, como hemos venido subrayando, entre los textos de las narrado-

9 Siguiendo con el juego de los dobles nos remitimos de nuevo a los argumentos de Carolyn Wolfenzon para quien en la novela de Nettel se estable este mismo juego en clave nacional: «en El huésped, el juego de la doble personalidad de la protagonista se yuxtapone al doble externo que es la ciudad de México. La novela parte de la noción de que existen dos Méxicos: por un lado, el visible y moderno; por otro, el subterráneo, que es a su vez la base y la constitución del primero» (2017: 42). Para agregar más adelante: «Además de los fantasmas que aparecen en esta novela reforzando los momentos claves de la historia reciente mexicana - la violencia en Tlatelolco, el terremoto de 1985, el narcotráfico y los carteles de las drogas que se disparan en todo el territorio de manera violentísima, la corrupción política, las relaciones entre raza y clase- que son como fantasmas atemporales; también, como en El huésped, aparece nuevamente la idea de los dos Méxicos, pero esta vez ya no es el México campesino y anticapitalista contra el México neoliberal, simbolizando en la primera novela de Nettel en el mundo de arriba (la ciudad) y el mundo de abajo (el metro), sino que la división de los Méxicos se encuentra dentro de la familia burguesa de la protagonista» (2017: 48). 
ras de hoy que utilizan los recursos que les ofrece lo insólito para indagar en la identidad, algo que no vemos esté presente de manera palmaria en los textos de la zacatecana. $Y$ al hilo de lo que acabamos de apuntar convendría sacar a colación las palabras de Benito García-Valero quien sistematiza el debate genérico sobre lo inusual presentando claves de análisis significativas que bien podrían agruparse en la gran cuestión que fundamenta la singular narrativa de estas narradoras: la reflexión identitaria. Una indagación intimista acerca de la identidad para la que se utilizan diversos recursos formales como «el apropiamiento de motivos de la literatura fantástica clásica para explorar posibilidades identitarias, como el doble» (García-Valero, 2019: 327) y, sobre todo, el trabajo con el espacio significativo del cuerpo.

La obra de Nettel, tras esos primeros capítulos en los que se nos describe los cambios que va percibiendo la protagonista se interna en otros discursos que remiten al submundo, poblado por ciegos, y que nos llevaría hasta el «Informe de ciegos», de Sobre héroes y tumbas (1961), de Ernesto Sábato, protagonizado por Fernando Vidal. Incluso este universo de los ciegos le sirve a la protagonista para conseguir la tan ansiada identidad tal como leemos en las palabras de Inés Ferrero Cárdenas: «Asociando a los ciegos con su parásito, Ana intuye que, si consigue entenderlos a ellos, conseguirá entender al Huésped, y por lo tanto estará más cerca de la posibilidad de entenderse a sí misma» (2009: 59).

Lo que es innegable es que la autora de El huésped, al igual que la narradora de «El huésped», configuran atmósferas cerradas, asfixiantes para sus protagonistas, que son seres desequilibrados, por momentos dementes, que se mueven entre el filo de la realidad con entradas a un fantástico que se mezcla con lo onírico y que perturba al lector que es finalmente quien tiene que decidir, si así lo estima oportuno entre una realidad u otra.

Amparo Dávila creó universos propios, decididamente personales, que supo diseñar con un lenguaje que encerraba algunas claves de los universos fantásticos que las narradoras actuales han sabido asumir y aprovechar de diferentes maneras. Su mirada decidida hacia lo femenino ha sido otro acicate para conformar el tema de la identidad tan marcado en los textos de las narradoras que hemos analizado y que en ocasiones se manifiesta a través del rendimiento de la utilización del doble. Las escritoras davilianas han sabido aprehender de la zacatecana la sutil ductilidad de sus atmósferas, la productividad de lo ambiguo. La genealogía daviliana está asegurada. 
BiBLIOGRAFÍA

Alemany Bay, Carmen (2016): «Narrar lo inusual. Bestiaria vida de Cecilia Eudave y El animal sobre la piedra de Daniela Tarazona», Romance Notes, 56 (1), pp. 131-141.

— (2019): «¿Una nueva modalidad de lo insólito en tiempos posmodernos? La narrativa de lo inusual», en Natalia Álvarez Méndez y Ana Abello Verano (coord.), Realidades fracturadas. Estéticas de lo insólito en la narrativa en lengua española (1980-2018), Visor, Madrid, pp. 307-324.

- (2020): «Lo insólito y lo femenino en algunas narradoras latinoamericanas actuales», Hispamérica, 145, pp. 3-12.

Álvarez Rivera, Adriana (2016): Ambigüedad y subversión fantástica en la narrativa de Amparo Dávila, Tesis doctoral, Universidad de Salamanca, disponible en $<$ https: / / dialnet.unirioja.es / servlet $/$ tesis?codigo $=155466>$ [10/09/2020].

Benedetti, Mario (1965): «Horror al alcance de todos», La Mañana, Suplemento «Al pie de las letras», Montevideo, 30 de julio.

CANo, Elsa (s/f): «El huésped de Guadalupe Nettel», El búho, disponible en <https: / / www.revistaelbuho.com / articolo.php?act=articolo\&id_articolo=371\&id_categoria $=40>[14 / 09 / 2020]$.

CARrera Garrido, Miguel (2018): «Silencios y metáforas: analogías en el uso de la ambigüedad en "El huésped" de Amparo Dávila y el cine de terror (pos)moderno», Brumal. Revista de Investigación sobre lo Fantástico, vol. VI, núm. 2, pp. 187206, disponible en < https:/ /ddd.uab.cat/pub/brumal/brumal_a2018v6n2 / brumal_a2018v6n2p187.pdf> [14/11/2020].

CAstro Ricalde, Maricruz (2017): “"Ptosis" de Guadalupe Nettel y otras historias sobre la violencia», Revista chilena de Literatura, 95, pp. 61-84, disponible en <https:/ / scielo. conicyt.cl/pdf/rchilite/n95/0718-2295-rchilite-95-00061.pdf > [7/10/2020].

DÁvila, Amparo (2004): «El canto de las sirenas», en Marco Tulio Aguilera Garramuño y Fernando Burgos (eds.), Los escritores y la creación en Hispanoamérica, Madrid, Castalia, pp. 451-454.

- (2009): Cuentos reunidos, Fondo de Cultura Económica / Letras Mexicanas, México.

Domínguez, Michael Christopher (2007): Diccionario crítico de la literatura mexicana (1955-2005), Fondo de Cultura Económica, México.

Estrada, Oswaldo (2014): Ser mujer y estar presente. Disidencias de género en la narrativa mexicana contemporánea, UNAM, Ciudad de México.

Eudave, Cecilia (2006): Registro de imposibles, Ediciones del Plenilunio, Guadalajara, $2^{\text {a }}$ edición ampliada.

- (2013): En primera persona, Ediciones Amargord, Madrid.

- (2015): Diferencias, alteridades e identidad (Narrativa mexicana de la primera mitad del siglo XX), Universidad de Alicante, Alicante.

- (2018): Bestiaria vida, Eolas Ediciones, León.

— (2020): «Polvo otoñal», Luvina, 99, disponible en https: / / luvina.com.mx / foros / index. php?option=com_content\&task=view\&id=3975\&Itemid $=88>[17 / 11 / 2020]$.

Ferrero CárdenAs, Inés (2009): «Geografía en el cuerpo. El otro yo en El huésped, de Guadalupe Nettel», Revista de literatura mexicana contemporánea, 15.4, pp. 55-62. 
GARCíA, Beatriz (2020): «Fallece la “insólita” Amparo Dávila, madre del cuento fantástico mexicano», Al día, disponible en <https: / / aldianews.com/es / articles / culture / literature / fallece-la-insolita-amparo-davila-madre-del-cuento-fantastico-mexicano $>$ [13-11-2020].

García, Mara L. (2017): «Huésped e invasores fantásticos en la cuentística de Amparo Dávila», Journal of Foreign Languages, Cultures and Civilizations, 1, pp. 34-39, disponible en <https: / / doi.org/10.15640/jflcc.v5n1a5> [10-09-2019].

García Peña, Leticia Lilia (2018): «La soledad metafísica en Árboles petrificados de Amparo Dávila», Agathos, 17, pp. 55-94, disponible en <https://webcache. googleusercontent.com/ search?q=cache:wBEGyQpMrcMJ:https: / / docplayer. es / 97796987-La-soledad-metafisica-en-arboles-petrificados-de-amparodavila-the-metaphysical-loneliness-in-arboles-petrificados-by-amparodavila.ht$\mathrm{ml}+\& \mathrm{~cd}=1 \& \mathrm{hl}=\mathrm{es} \& \mathrm{ct}=\mathrm{clnk} \& \mathrm{gl}=\mathrm{es} \& \mathrm{client}=$ safari $>$ [03-09-2019].

García-VAlero, Benito (2019): «Para una teoría de lo inusual. Procedimientos lingüísticos, planteamientos estéticos», en Natalia Álvarez Méndez y Ana Abello Verano (coord.), Realidades fracturadas. Estéticas de lo insólito en la narrativa en lengua española (1980-2018), Visor, Madrid, pp. 325-338.

Glantz, Margo (2001 [1994]): «Las hijas de la Malinche», en Margo Glantz (coord.), La Malinche, sus padres y sus hijos, Taurus, Ciudad México, pp. 277-303.

GonZÁlez, Héctor (2020): «Amparo Dávila (1928-2020) la escritora que a partir de lo insólito cuestionó la realidad», disponible en https://aristeguinoticias. com/1904/ kiosko/ amparo-davila-1928-2020-la-escritora-que-a-partir-de-loinsolito-cuestiono-la-realidad/ [14-10-2020].

GonZÁlez Zimmer, Aída T. (2019): «La mirada en los cuentos de Amparo Dávila» (TFG), Universidad de Zaragoza, disponible en https:/ / zaguan.unizar.es/ record / 87986 / files / TAZ-TFG-2019-4269.pdf [16-11-2020].

HIND, Emily (2005): «El consumo textual y La cresta de Ilión de Cristina Rivera Garza», Revista de Filología y Lingüistica de la Universidad de Costa Rica, 31 (1), pp. 35-50.

Lemus, Rafael (2009): «Cuentos reunidos de Amparo Dávila», Letras Libres, disponible en <https: / / www.letraslibres.com > autor > rafael-lemus> [03-09- 2019].

LoREnzo, Jaime (1995): «La narrativa de Amparo Dávila», Temas y variaciones de literatura, 6, pp. 49-64, disponible en <http://zaloamati.azc.uam.mx/handle $/ 11191 / 1386$ ? show =full $>$ [Consultado 03-09-2019]

Luna Martínez, América (2008): «Amparo Dávila o la feminidad contrariada», Espéculo. Revista de Estudios Literarios, 39, disponible en <http: / / www.ucm.es/info/ especulo/numero39/adavila.html > [03-09-2019].

MAta JuÁrez, Óscar (2008): «La mirada deshabitada: la narrativa de Amparo Dávila», Tema y variaciones de literatura: escritoras mexicanas del Siglo xx, 12, pp. 13-24, disponible en <http://zaloamati.azc.uam.mx/handle/11191/1499?show=full> [02-09-2019].

Mercado, Gabriela (2007): «Diálogo con la obra de Amparo Dávila y resolución de problemas de género en La cresta de Ilión de Cristina Rivera Garza», Revista de Humanidades, 22, pp. 45-75.

Nettel, Guadalupe (2006): El huésped, Anagrama, Barcelona. 
Ríos Baeza, Felipe A. (2019): «Una novela hospitalaria: La cresta de Ilión, de Cristina Rivera-Garza», Valenciana, 24, julio-diciembre, pp. 95-117.

Rivera Garza, Cristina (2002): La cresta de Ilión, Tusquets, Barcelona.

Rovecchio Antón, Laeticia (2020): «Cristina Rivera Garza: “En La cresta de Ilión la desaparición cultural va ligada con la violencia física" ", PliegoSuelto, disponible en <http: / / www.pliegosuelto.com/ ?p=29892> [02-09-2019].

SAnZ, Marta (6/06/2020): «La pertenencia de los límites», El País, disponible en $<$ https: / / elpais.com/cultura/2020/06/04/babelia/1591256898_887708.html> [13-11-2020].

SAUNERO-WARD, Verónica (2006): «La cresta de Ilión: lo fantástico posmoderno», La palabra y el hombre, 137, enero-marzo, pp. 173-183.

Velasco Vargas, Magali (2007): El cuento: la casa de lo fantástico, Fondo Editorial Tierra Adentro, Ciudad de México.

Vélez García, Juan Ramón (2015): Noches oscuras del alma y del cuerpo. Alteridad y eros transgresivo en la cuentística de Francisco Tario, Tesis Doctoral. Universidad de Salamanca, disponible en <http: / / hdl.handle.net / 10366/128302> [10-09- 2019].

Wolfenzon, Carolyn (2017): «El fantasma que nos habita: El huésped y El cuerpo en que nací de Guadalupe Nettel como espejo político de México», Latin American Literary Review, 44 (88), pp. 41-51.

Zaca Guevara, María Reyna (2005): Los cuentos de Amparo Dávila y La cresta de Ilión de Cristina Rivera Garza: un diálogo intertextual (Tesis de Maestría), BUAP, Universidad de Puebla. 